\title{
Fat-soluble vitamins in cystic fibrosis
}

\author{
BY ROSEMARY J. RA YNER \\ Regional Child Development Centre, St. James's University Hospital, Leeds LS9 7TF
}

When cystic fibrosis (CF) was first recognized (Andersen, 1939), symptoms and signs of deficiency of vitamin A were common in infants with the condition. It was realized that pancreatic insufficiency from birth caused fat malabsorption and, therefore, malabsorption of the fat-soluble vitamins $\mathrm{A}, \mathrm{D}, \mathrm{E}$ and $\mathrm{K}$. With the use of pancreatic enzyme replacement therapy and routine vitamin supplementation, clinical problems arising from deficiencies of the fat-soluble vitamins became uncommon in children with $\mathrm{CF}$. However, CF patients are still at risk from vitamin deficiency if the diagnosis is made late (Brooks et al. 1990), if part of the small bowel has been resected (Bye et al. 1985) or if fat-soluble vitamin supplements are not taken (O'Donnell \& Talbot, 1987). In addition, it has been recognized that factors other than simple malabsorption of fat may be important. For example, patients with CF have low circulating levels of retinol-binding protein, which is essential for the transport of retinol from the liver to the tissues (Rees Smith et al. 1972). Some patients may have low serum levels of retinol and retinolbinding protein despite raised liver concentrations of retinol, suggesting that its release from liver stores is impaired (Underwood \& Denning, 1972). Reduced enterohepatic circulation of bile acids may also contribute to malabsorption of fat-soluble vitamins from the small bowel (Weber \& Roy, 1985). In addition, patients with liver function abnormalities may have inadequate 25 -hydroxylation of vitamin D (Friedman et al. 1985).

The fat-soluble vitamin status of thirty-six infants consecutively identified by screening in Denver, Colorado was reported recently (Sokol et al. 1989). At a mean age of 51 (SE 26.7) $\mathrm{d}, 21 \%$ had low serum levels of retinol, $35 \%$ low 25 -hydroxycholecalciferol levels and $38 \%$ low $\alpha$-tocopherol levels and low total serum vitamin E:total lipids ratios. After treatment with pancreatic enzymes and vitamin supplements, all patients had normal serum levels of retinol and 25-hydroxycholecalciferol by 6 months of age but $10 \%$ remained vitamin $\mathrm{E}$ deficient. None of the infants had evidence of vitamin $\mathrm{K}$ deficiency.

The vitamin status of thirty-six older patients in Leeds was investigated in 1981 in order to assess the adequacy of conventional vitamin supplementation and the effect of short-term supplementation with water-miscible forms of vitamin $A$ and $E$ (Congden et al. 1981). At that time patients were not receiving vitamin $E$ supplements and serum vitamin E levels were low in $90 \%$ of patients and inversely correlated with the severity of the steatorrhoea, but responded well to treatment with $50 \mathrm{mg}$ water-miscible vitamin $\mathrm{E}$ daily for 2 weeks. Despite receiving $1.2 \mathrm{mg}$ oil-based vitamin A supplements daily, $40 \%$ of patients had low serum retinol levels and these correlated with the retinol-binding protein levels. Serum levels of retinol responded well to 2 weeks of treatment with 1.2 mg water-miscible vitamin A daily. Seven of twenty (35\%) patients receiving vitamin D supplements (10 $\mu \mathrm{g}$ daily) had serum levels lower than $15 \mathrm{ng} / \mathrm{ml}$ and two $(10 \%)$ had levels below the normal range. Unfortunately, water-miscible preparations of vitamin A and vitamin $E$ are not readily available on prescription in the UK and tend to be rather unstable if stored for long periods. Therefore, most CF patients are still prescribed 
standard oil-based vitamin preparations. Many of the older children and adults with $\mathrm{CF}$ in Leeds now receive $2.4 \mathrm{mg}$ vitamin $A$ and $20 \mu \mathrm{g}$ vitamin D daily in the form of two vitamin $A$ and $D$ capsules, in addition to $100-200 \mathrm{mg}$ vitamin $E$ daily. Optimizing the dose of pancreatic enzyme supplements by estimation of faecal fat excretion is obviously important. Regular monitoring of serum levels of fat-soluble vitamins is essential so that vitamin supplementation can be adjusted to meet the needs of each individual patient.

\section{VITAMIN K}

In the newborn, it is important to be aware of the possibility of vitamin K deficiency as a complication of CF, presenting as haemorrhagic disease (Torstenson et al. 1970), (Walters \& Koch, 1972). Most maternity units now administer prophylactic vitamin K $1 \mathrm{mg}$ orally to all newborn babies, but babies with respiratory problems and those with meconium ileus should receive vitamin $\mathrm{K}$ intramuscularly on admission to the neonatal unit (McNinch et al. 1985). Babies with prolonged neonatal jaundice are particularly at risk and the prothrombin time should be monitored regularly in any $\mathrm{CF}$ patient with significant liver disease (Corrigan et al. 1981). Older children with CF have normal plasma levels of vitamin $K_{1}$ and routine supplementation with vitamin $K$ is not considered necessary (Choonara et al. 1989).

\section{VITAMIN D}

It is perhaps surprising that rickets has been described so rarely in CF (Scott et al. 1977). This may be due to the fact that dermal synthesis of vitamin $\mathrm{D}$ accounts for more than $80 \%$ of normal requirements. It has been shown that serum levels of 25 hydroxycholecalciferol vary as would be expected with latitude and seasonal variations in sunlight exposure (Reiter et al. 1985; Thompson, 1987). However, most studies involving adolescents and adults with CF have shown that serum levels of 25-hydroxycholecalciferol are low compared with age-matched controls and that some patients have evidence of secondary hyperparathyroidism (Hahn et al. 1979; Stead et al. 1988). Measurements of bone mineralization have been made using photon absorptiometry and have shown a significant reduction in bone mineral index compared with age-matched controls. Adolescent girls appear to be most at risk (Mischler et al. 1979). Symptomatic osteomalacia has been described in a 25 -year-old male patient with previously undiag. nosed CF and cirrhosis (Friedman et al. 1985), but has not been described in adults with $\mathrm{CF}$ who have been receiving vitamin $\mathrm{D}$ supplementation.

\section{VITAMIN E}

Neurological problems due to long-standing vitamin E deficiency in patients with CF have been recognized mainly in CF adults during the last decade (Sitrin et al. 1987; Cynamon et al. 1988). Early signs include absent deep tendon reflexes and loss of position sense and vibration sense in the lower limbs. Nerve conduction studies may demonstrate increased sural nerve conduction latency and decreased action potential amplitude. Visual evoked potentials amd somatosensory evoked potentials may also be abnormal (Kaplan et al. 1988). More severely affected patients present with dysarthria, tremor, ataxia, proximal muscle weakness and decreased visual acuity. Post mortem 
there is degeneration of the posterior columns, loss of large unmyelinated axons in peripheral nerves and retinal degeneration. Since the clinical effects of vitamin $E$ deficiency have been recognized, it has become routine to prescribe vitamin $E$ supplements to patients with CF, and ideally the serum vitamin E:total lipids ratio should be measured regularly and supplements adjusted accordingly (Sokol et al. 1984). When a group of thirty patients in Leeds was supplemented with $50 \mathrm{mg}$ water-miscible vitamin $\mathrm{E}$ daily for a period of 18-24 months, there was a progressive rise in mean serum vitamin $E$ levels from 3.61 to $8.30 \mathrm{mg} / 1(P<0.001)$ over the period of the study and this was accompanied by a small but significant increase in mean haemoglobin from 131.4 to 134.7 $\mathrm{g} / \mathrm{l}(P<0.01)$ (Kelleher et al. 1987). This effect is most likely to be due to increased erythrocyte survival time once vitamin $\mathrm{E}$ deficiency is corrected, since vitamin $\mathrm{E}$ deficiency is a recognized cause of haemolytic anaemia in low-birth-weight infants (Oski \& Barness, 1967).

Vitamin E may also be important in controlling the progression of lung disease in CF. A proportion of the lung injury which occurs is thought to be due to the host inflammatory response, in particular the release of free radicals and proteolytic enzymes from neutrophils (Pier, 1985). The antioxidant properties of $\alpha$-tocopherol are thought to protect tissues from damage by free radicals and stabilize cell membranes (Bieri et al. 1983). However, there are as yet no long-term studies of vitamin E supplementation in CF which have been able to show a beneficial effect on the lung.

\section{VITAMIN A}

Retinol is essential for the synthesis of rhodopsin in the retina and for the maintenance of secretory epithelia (Wolf, 1984). An early symptom of vitamin A deficiency is night blindness, but this may not be reported by young CF patients unless they are specifically asked. Prolonged vitamin A deficiency leads to keratinizing squamous metaplasia of the conjunctiva, leading to conjunctival xerosis and eventually to xerophthalmia with corneal ulceration (Petersen et al. 1968). Rarely in infancy, vitamin A deficiency may present with symptoms and signs of raised intracranial pressure (Abernathy, 1976; Eid et al. 1990). Night blindness was reported in two older children who had been receiving vitamin A supplementation (Fulton et al. 1982). In a study carried out in Nottingham, a group of thirty-one unselected and twelve selected patients with a median age of 16 years (range 8-46 years) performed dark adaptation tests and were examined by an ophthalmologist (Rayner et al. 1989). The latter group were known to have had low serum levels of retinol. Eight patients had abnormally high dark adaptation thresholds, although only four admitted to noticing symptoms. Two of these and one other patient had conjunctival xerosis (Vernon et al. 1989). The median serum retinol level in the nine affected patients was only 0.5 (range $0.2-1.4) \mu \mathrm{mol} / 1$ compared with $1.1(0.5-2.3) \mu \mathrm{mol} / 1$ in the thirty-four unaffected patients $(P=0.002)$. There was a rapid rise in dark adaptation threshold for values of serum vitamin $A$ below $0.7 \mu \mathrm{mol} / /$. Retinol-binding protein levels were also significantly depressed in the affected group but vitamin $\mathrm{E}$ levels were similar. Six of the nine affected patients had abnormal liver function and three admitted to poor compliance with vitamin supplementation. Five patients were treated with high doses of water-miscible vitamin A in order to replenish liver stores (StewartTruswell, 1985) and daily supplements of oil-based vitamin A were then adjusted according to serum levels. Dark adaptation thresholds improved rapidly in all except one 
patient, who had a very low serum level of retinol-binding protein. Conjunctival xerosis was slow to respond to treatment in two brothers until zinc supplements were given in addition to vitamin $\mathrm{A}$. $\mathrm{Zn}$ is required for the release of vitamin $\mathrm{A}$ and retinol-binding protein from liver stores and acts as a coenzyme for retinol dehydrogenase ( $E C$ 1.1.1.105) in the retina (Solomons \& Russell, 1980).

Whilst clinical problems directly attributable to vitamin A deficiency are relatively uncommon in CF, the effects of sub-clinical deficiency on the progression of lung disease are not known. Animals made deficient in vitamin A commonly die from respiratory and genito-urinary infections before the eye lesions of xerophthalmia are established. Children in the Third World with mild vitamin A deficiency are at increased risk of respiratory disease and diarrhoea and have an increased mortality rate compared with children who are not vitamin A deficient (Sommer et al. 1984). Increased bacterial binding to respiratory epithelial cells has been demonstrated in vitamin A deficiency (Chandra, 1988). A clinical trial of vitamin A supplementation in preterm infants susceptible to bronchopulmonary dysplasia suggested that there was some benefit (Shenai et al. 1987). Studies need to be performed in CF to assess the long-term effects of vitamin A deficiency on the lung disease. Techniques such as conjunctival impression cytology may prove to be useful as a way of monitoring vitamin A status (Tseng, 1985).

\section{CONCLUSIONS}

As the prognosis for CF patients has improved, clinical problems due to fat-soluble vitamin deficiencies have been recognized again. The patients most at risk are those with severe malabsorption or poor compliance and those with liver disease. When adolescents and young adults are transferred to the care of adult physicians, less attention may be paid to the nutritional aspects of CF in the face of severe and sometimes life-threatening pulmonary complications. It is, therefore, essential that those of us who care for CF patients during childhood educate them and their families about the importance of taking vitamin supplements and enquire specifically about early symptoms of vitamin deficiency.

\section{REFERENCES}

Abernathy, R. S. (1976). Bulging fontanelle as presenting sign in cystic fibrosis. American Journal of Diseases in Children 130, 1360-1362.

Andersen, D. H. (1939). Cystic fibrosis of the pancreas, vitamin A deficiency and bronchiectasis. Journal of Pediatrics 15, 763-771.

Bieri, J. G., Corash, L. \& Van Hubbard, S. (1983). Medical uses of vitamin E. New England Journal of Medicine 308, 1063-1071.

Brooks, H. L., Driebe, W. T. \& Schemmer, G. G. (1990). Xerophthalmia and cystic fibrosis. Archives of Ophthalmology 108, 354-357.

Bye, A. M. E., Muller, D. P. R., Wilson, J., Wright, V. M. \& Mearns M. B. (1985). Symptomatic vitamin E deficiency in cystic fibrosis. Archives of Disease in Childhood 60, 162-164.

Chandra, R. K. (1988). Increased bacterial binding to respiratory epithelial cells in vitamin A deficiency. British Medical Journal 297, 834-835.

Choonara, I. A., Winn, M. J., Park, B. K. \& Littlewood, J. M. (1989). Plasma vitamin K concentrations in cystic fibrosis. Archives of Disease in Childhood 64, 732-734.

Congden, P. J., Bruce, G., Rothburn, M. M., Clarke, P. C. N., Littlewood, J. M., Kelleher, J. \& Losowsky, M. S. (1981). Vitamin status in treated patients with cystic fibrosis. Archives of Disease in Childhood 56, $708-714$. 
Corrigan, J. J., Taussig, L. M., Beckerman, R. \& Wagener, J. S. (1981). Factor II (prothrombin) coagulant activity and immunoreactive protein: detection of vitamin $\mathrm{K}$ deficiency and liver disease in patients with cystic fibrosis. Journal of Pediatrics 99, 254-257.

Cynamon, H. A., Milov, D. E., Valenstein, E. \& Wagner, M. (1988). Effect of vitamin E deficiency on neurologic function in patients with cystic fibrosis. Journal of Pediatrics 113, 637-640.

Eid, N. S., Shoemaker, L. R. \& Samiec, T. D. (1990). Vitamin A in cystic fibrosis: case report and review of the literature. Journal of Pediatric Gastroenterology and Nutrition 10, 265-269.

Friedman, H. Z., Langman, C. B. \& Favus, M. J. (1985). Vitamin D metabolism and osteomalacia in cystic fibrosis. Gastroenterology 88, 808-813.

Fulton, A. B., Hansen, R. M., Underwood, B. A., Shwachman, H. \& Barg, D. C. (1982). Scotopic thresholds and plasma retinol in cystic fibrosis. Investigations in Ophthalmology and Visual Science 23, 364-370.

Hahn, T. J., Squires, A. E., Halstead, L. R. \& Strominger, D. B. (1979). Reduced serum 25-hydroxyvitamin $\mathrm{D}$ concentration and disordered mineral metabolism in patients with cystic fibrosis. Journal of Pediatrics 94 , 38-42.

Kaplan, P. W., Rawal, K., Erwin, C., D’Souza, B. J. \& Spock, A. (1988). Visual and somatosensory evoked potentials in vitamin $\mathrm{E}$ deficiency with cystic fibrosis. Electroencephalography and Clinical Neurophysiology 71, 266-272.

Kelleher, J., Miller, M. G., Littlewood, J. M., McDonald, A. M. \& Losowsky, M. S. (1987). The clinical effect of correction of vitamin $\mathrm{E}$ depletion in cystic fibrosis. International Journal for Vitamin and Nutrition Research 57, 253-259.

McNinch, A. W., Upton, C., Samuels, M., Shearer, M. J., McCarthy, P., Tripp, J. H. \& Orme, R. L'E. (1985). Plasma concentrations after oral or intramuscular vitamin K1 in neonates. Archives of Disease in Childhood 60, 814-818.

Mischler, E. H., Chesney, P. J., Chesney, R. W. \& Mazess, R. B. (1979). Demineralization in cystic fibrosis. American Journal of Diseases in Children 133, 632-635.

O'Donnell, M. \& Talbot, J. F. (1987). Vitamin A deficiency in treated cystic fibrosis: case report. British Journal of Ophthalmology 71, 787-790.

Oski, F. A. \& Barness, L. A. (1967). Vitamin E deficiency: a previously unrecognized cause of hemolytic anemia in the premature infant. Journal of Pediatrics 70, 211-220.

Petersen, R. A., Petersen, V. S. \& Robb, R. M. (1968). Vitamin A deficiency with xerophthalmia and night blindness in cystic fibrosis. American Journal of Diseases in Children 116, 662.

Pier, G. B. (1985). Pulmonary disease associated with Pseudomonas aeruginosa in cystic fibrosis: current state of the host-bacterium interaction. Journal of Infectious Diseases 151, 575-580.

Rayner, R. J., Tyrrell, J. C., Hiller, E. J., Marenah, C., Neugebauer, M. A., Vernon, S. A. \& Brimlow, G. (1989). Night blindness and conjunctival xerosis due to vitamin A deficiency in cystic fibrosis. Archives of Disease in Childhood 64, 1151-1156.

Rees Smith, F., Underwood, B. A., Denning, C. R., Varma, A. \& Goodman, D. S. (1972). Depressed plasma retinol-binding protein levels in cystic fibrosis. Journal of Clinical and Laboratory Medicine 80, 423-433.

Reiter, E. O., Brugman, S. M., Pike, J. W., Pitt, M., Dokoh, S., Haussler, M. R., Gerstle, R. S. \& Taussig, L. M. (1985). Vitamin D metabolites in adolescents and young adults with cystic fibrosis: effects of sun and season. Journal of Pediatrics 106, 21-26.

Scott, J., Elias, E., Moult, P. J. A., Barnes, S. \& Wills, M. R. (1977). Rickets in adult cystic fibrosis with mypoathy, pancreatic insufficiency and proximal renal tubular dysfunction. American Journal of Medicine 63, $488-492$.

Shenai, J. P., Kennedy, K. A., Chytil, F. \& Stahlman, M. T. (1987). Clinical trial of vitamin A supplementation in infants with bronchopulmonary dysplasia. Journal of Pediatrics 111, 269-277.

Sitrin, M. D., Lieberman, F., Jensen, W. E., Noronha, A., Milburn, C. \& Addington, W. (1987). Vitamin E deficiency and neurologic disease in adults with cystic fibrosis. Annals of Internal Medicine 107, 51-54.

Sokol, R. J., Heubi, J. E., Iannaconne, S. T., Bove, K. E. \& Balistreri, W. F. (1984). Vitamin E deficiency with normal serum vitamin $\mathrm{E}$ concentrations in children with chronic cholestasis. New England Journal of Medicine 310, 1209-1212.

Sokol, R. J., Reardon, M. C., Accurso, F. J., Stall, C., Narkewicz, M., Abman, S. H. \& Hammond, K. B. (1989). Fat-soluble vitamin status during the first year of life in infants with cystic fibrosis identified by screening of newborns. American Journal of Clinical Nutrition 50, 1064-1071.

Solomons, N. W. \& Russell, R. M. (1980). The interaction of vitamin A and zinc: implications for human nutrition. American Journal of Clinical Nutrition 33, 2031-2040. 
Sommer, A., Katz, J. \& Tarwotjo, I. (1984). Increased risk of respiratory disease and diarrhoea in children with coexisting mild vitamin A deficiency. American Journal of Clinical Nutrition 40, 1090-1095.

Stead, R. J., Houlder, S., Agnew, J., Thomas, M., Hodson, M. E., Batten, J. C. \& Dandona, P. (1988). Vitamin $\mathrm{D}$ and parathyroid hormone and bone mineralisation in adults with cystic fibrosis. Thorax 43, 190-194.

Stewart-Truswell, A. (1985). Malnutrition in the Third World - II. British Medical Journal 291, 587-588.

Thompson, G. N. (1987). Determinants of serum vitamin D levels in preadolescent cystic fibrosis children. Acta Paediatrica Scandinavica 76, 962-964.

Torstenson, O. L., Bennett-Humphrey, G., Edson, J. R. \& Warwick, W. J. (1970). Cystic fibrosis presenting with severe haemorrhage due to vitamin $\mathrm{K}$ malabsorption: a report of three cases. Pediatrics 45, 857-861.

Tseng, S. C. S. (1985). Staging of conjunctival squamous metaplasia by impression cytology. Ophthalmology 92, 728-733.

Underwood, B. A. \& Denning, C. R. (1972). Blood and liver concentrations of vitamins A and $E$ in children with cystic fibrosis. Pediatric Research 6, 26-31.

Vernon, S. A., Neugebauer, M. A. Z., Brimlow, G., Tyrrell, J. C. \& Hiller, E. J. (1989). Conjunctival xerosis in cystic fibrosis. Journal of the Royal Society of Medicine 42, 46-47.

Walters, T. R. \& Koch, H. F. (1972). Haemorrhagic diathesis and cystic fibrosis in infancy. American Journal of Diseases in Children 124, 641-642.

Weber, A. M. \& Roy, C. C. (1985). Bile acid metabolism in children with cystic fibrosis. Acta Paediatrica Scandinavica 74, Suppl. 317, 9-15.

Wolf, G. (1984). Multiple functions of vitamin A. Physiological Reviews 64, 873-937. 